\title{
Coarse root spatial distribution determined using a ground-penetrating radar technique in a subtropical evergreen broad-leaved forest, China
}

\author{
YAN Hui $^{1,2,3}$, DONG XinLiang ${ }^{1,2}$, FENG Gang $^{1,2}$, ZHANG ShouRen $^{1 *}$ \\ \& MUCCIARDI Anthony ${ }^{4}$ \\ ${ }^{1}$ State Key Laboratory of Vegetation and Environmental Change, Institute of Botany, Chinese Academy of Sciences, Beijing 100093, China; \\ ${ }^{2}$ University of Chinese Academy of Sciences, Beijing 100049, China; \\ ${ }^{3}$ Inner Mongolia Forestry Monitoring and Planning Academy, Hohhot 010020, China; \\ ${ }^{4}$ TreeRadar, Inc., Silver Spring, MD 20910, USA
}

Received March 20, 2013; accepted August 12, 2013

\begin{abstract}
Coarse roots play a critical role in forest ecosystems and both abiotic and biotic factors affect their spatial distribution. To some extent, coarse root density may reflect the quantity of root biomass and biotic competition in forests. However, using traditional methods (e.g., excavation) to study coarse roots is challenging, because those methods are time-consuming and laborious. Furthermore, these destructive methods cannot be repeated in the same forests. Therefore, the discovery of non-destructive methods for root studies will be very significant. In this study, we used a ground-penetrating radar technique to detect the coarse root density of three habitats (ridge, slope and valley) and the dominant tree species (Castanopsis eyrei and Schima superba) in a subtropical forest. We found that (i) the mean of coarse root density for these three habitats was 88.04 roots $\mathrm{m}^{-2}$, with roots being mainly distributed at depths of $0-40 \mathrm{~cm}$. Coarse root densities were lower in deeper soils and in areas far from the trunk. (ii) Coarse root densities differed significantly among the three habitats studied here with slope habitat having the lowest coarse root density. Compared with $S$. superba, C. eyrei had more roots distributed in deeper soils. Furthermore, coarse roots with a diameter $>3 \mathrm{~cm}$ occurred more frequently in the valleys, compared with root densities in ridge and slope habitats, and most coarse roots occurred at soil depths of 20-40 cm. (iii) The coarse root density correlated negatively with tree species richness at soil depths of 40-60 cm. The abundances of the dominant species, such as C. eyrei, Cyclobalanopsis glauca, Pinus massoniana, had significant impacts on coarse root density. (iv) The soil depth of 0-40 cm was the "basic distribution layer" for coarse roots since the majority of coarse roots were found in this soil layer with an average root density of 84.18 roots $\mathrm{m}^{-2}$, which had no significant linear relationships with topography, tree species richness, rarefied tree species richness and tree density. Significant relationships between coarse root density and these factors were found at the soil depth of $40-60 \mathrm{~cm}$, which was the "potential distribution layer" for coarse root distribution.
\end{abstract}

abiotic factors, biotic factors, coarse root density, ground-penetrating radar (GPR), spatial distribution

Citation: Yan H, Dong X L, Feng G, et al. Coarse root spatial distribution determined using a ground penetrating radar technique in a subtropical evergreen broad-leaved forest, China. Sci China Life Sci, 2013, 56: 1038-1046, doi: 10.1007/s11427-013-4560-7

Coarse roots (diameter $>0.5 \mathrm{~cm}$ ) play an important role in forest ecosystems. Stover et al. [1] found that plants allo-

*Corresponding author (email: zsr@ibcas.ac.cn) cated surplus carbon to coarse roots in a $\mathrm{CO}_{2}$ enhancement experiment. Almost $75 \%$ of root biomass was allocated to coarse roots with a diameter $>2 \mathrm{~cm}[2]$. The study of coarse roots, however, is frequently neglected because of the limi- 
tations of traditional methods used to study roots $[3,4]$.

Excavation methods have been widely used to explore the spatial distribution of coarse roots, because excavation makes roots easily visible and the techniques are reliable. Jackson [5] analyzed the vertical root distributions of different species based on 250 root distribution studies which used excavation and concluded that $80 \%-90 \%$ of roots were distributed at depths of $0-30 \mathrm{~cm}$ in tundra, boreal coniferous forest and temperate steppe, while in deserts and temperate coniferous forests, only around 50\% of roots were distributed at that depth since more roots penetrated deeper than $30 \mathrm{~cm}$ in those habitats. In a pure fir forest, Li [6] indicated that fewer coarse roots were found at depths of $0-10 \mathrm{~cm}$, but the number increased at a depth of 20-30 cm. In Masson pine forest, Li and Fan [7] found that the maximum coarse root density occurred at a depth of $>40 \mathrm{~cm}$. Therefore, coarse roots are generally distributed at depths of 0-60 cm, but may be at depths of $0-30$ or $30-60 \mathrm{~cm}$, depending on tree species and their growth habitats. Coarse roots also have a horizontal distribution. Zhang et al. [8] indicated that coarse root numbers differed significantly with varying distance from the trunk.

The growth and distribution of roots are affected by environmental factors, e.g., soil physical and chemical characteristics [9] and terrain [10], which may also reflect the adaptation of plants to various environments [11]. Moreover, inter- or intra-species competition in belowground may be reflected by root density. Aside from environmental factors, biotic factors, such as neighboring individuals $[6,7,12,13]$, tree density [14], and diameter at breast height (DBH) of trees also affect the distribution of roots. In addition, tree size has been reported to affect root density generally, regardless of soil depth $[11,15]$. In summary, both abiotic and biotic factors have impacts on plant root growth and distribution. Analyzing the effects of these factors on roots could provide new insights into the spatial distribution of roots of various species.

Ground-penetrating radar (GPR) has been gradually introduced into the study of coarse roots in recent years. Based on the differences of dielectric capacity and the reflected waves of GPR and by analyzing the pattern, amplitude and reaction time of reflected waves which occur at an object-soil boundary, we were able to detect the location, architecture, morphology and depth of underground objects $[16,17]$. Studies on coarse roots using GPR will avoid damaging the trees and their microenvironments, as well as allow repeatable measurements at a larger spatial scale. Hence, GPR data would provide repeatable data collection options and more representative data than data collected by traditional methods. GPR has been used successively to locate coarse roots in forest soils, showing that GPR is a nondestructive method and can be used to effectively and efficiently study coarse roots [18,19]. Despite being one of the most challenging and important issues in belowground ecology, very few data are available on the spatial distribu- tions of coarse roots as well as the relationships between coarse roots and other biotic and abiotic factors, particularly as it relates to studies using the GPR technique. We used GPR to detect the spatial distributions of coarse roots nondestructively in an old-growth subtropical forest ecosystem, aiming to understand how coarse roots grew spatially and how abiotic and biotic factors affected their distribution.

\section{Materials and methods}

\subsection{Study site}

The subtropical broadleaved forest study site was located in a $24-\mathrm{hm}^{2}$ permanent plot in Gutianshan National Nature Reserve (GNNR) in Zhejiang Province, China. The GNNR covers $8107 \mathrm{hm}^{2}\left(29^{\circ} 10^{\prime} 19.4^{\prime \prime}-29^{\circ} 17^{\prime} 41.4^{\prime \prime} \mathrm{N}, 118^{\circ} 03^{\prime} 49.7^{\prime \prime}-\right.$ $\left.118^{\circ} 11^{\prime} 12.2^{\prime \prime} \mathrm{E}\right)$. Mean annual temperature is $15.3^{\circ} \mathrm{C}$. Total accumulate temperature of growing season is $5221.5^{\circ} \mathrm{C}$. Mean annual precipitation is $1963.7 \mathrm{~mm}$. The red, yellow-red, red-yellow and marsh soils of the study site have developed on granite. Dominant species in GNNR are $C$. eyrei, S. superba, P. massoniana, C. glauca, Daphniphyllum Oldham, Lithocarpus glaber, and Quercus glandulifera [20].

\subsection{Principles of GPR}

We used a GPR unit known as the TerraSIRch ${ }^{\text {TM }}$ Geophysical Survey Systems (Inc., Salem, New Hampshire, USA), which comprises a SIR-3000 (Subsurface Interface Radar) computer system and a signal launch system $(900 \mathrm{MHz}$, Model 3101B). TreeWin software (TreeRadar Inc., USA) was used to analyze the radar graphs. The maximum penetration depth at $900 \mathrm{MHz}$ is $1 \mathrm{~m}$ belowground with a resolution of $1.5 \mathrm{~cm}$.

The GPR detector and signal record system differentiates objects based on their water content. When root water content is higher than water content of the soil matrix, strong reflective waves will be generated at the root/soil boundary; roots with higher water content create brighter pixels on the radar graph when using TreeWin analysis software. Hence, based on the various conditions of reflective waves, a single coarse root can be recognized in the radar graph. At the same time, we measured the distance between the coming-in and outgoing signals for each root detected by TreeWin. Then we converted the radar signal-based distance into the actual root diameter by an empirical equation, which was established using 32 paired datasets of actual and signal-based root diameters obtained from nearby forests. The empirical equation is expressed as follows:

$$
Y_{\text {act_D }}=0.1127 X_{\text {meas_D }}+0.1102, R^{2}=0.5697,
$$

where $Y_{\text {act_D }}$ represents the actual root diameter determined using micrometer, and $X_{\text {meas_D }}$ represents the root diameter determined by TreeWin. Radar signals penetrate into the 
soil in the shape of a cone with the bottom of the cone forming an ellipse; then large-scale detection of coarse roots is achieved by moving/scanning using the GPR system. The signals are recorded every $5 \mathrm{~mm}$ of the GPR's motion, and we can calculate the number of coarse roots per unit area with the known scanning length and the short axis of the radar formed ellipse. We defined that as coarse root density.

\subsection{Experimental design}

There are two obvious ridges in the $24-\mathrm{hm}^{2}$ subtropical broadleaved forest plot at GNNR used in this study (Figure 1). Our experiment used the larger ridge along its north and south side with the total width of $400 \mathrm{~m}$. Five $10 \mathrm{~m} \times 10 \mathrm{~m}$ subplots were established on the ridge spaced $80 \mathrm{~m}$ apart. We also set up five subplots on the slope and five subplots in the valley. These 15 subplots were designed to represent five different altitudes based on the contour map of the 24-hm ${ }^{2}$ plot (Figure 1). First, we recorded the geographic information for each plot and then scanned the plots by GPR. Each linear scan was recorded manually as a file, with about 10 scanning files required for each plot.

Also, we selected 106 dominant C. eyrei trees and $32 \mathrm{~S}$. superba trees with DBH $>50 \mathrm{~cm}$ for analysis. Considering the evaluation of the effects of terrain, understory shrubs and herbs on radar scanning, we chose 14 C. eyrei and nine S. superba for further study.

For evaluation of the detailed layout of coarse roots for a single tree, a total of six parallel linear scans were conducted starting from the edge of the trunk. Each scanning line was $3 \mathrm{~m}$ long with a $0.5 \mathrm{~m}$ interval between scanning lines.
The measurements were conducted from July to October, 2011.

\subsection{Data analysis}

For each $10 \mathrm{~m} \times 10 \mathrm{~m}$ or $3 \mathrm{~m} \times 3 \mathrm{~m}$ experimental subplot, coarse root density was calculated by averaging the measurements of all scanning lines.

We used General Linear Model two-way ANOVA to detect the distribution of coarse root density and their associations with five elevations $(204.1,181.0,154.0,124.2$ and $102.9 \mathrm{~m}$ ) in the three habitats (ridge, slope and valley). We also tested the difference of coarse root distributions among three soil layers $(0-20,20-40$, and $40-60 \mathrm{~cm})$ at different elevations and habitats.

We identified the main abiotic components for topographical properties including elevation, convex/concave slope, slope and aspect at a scale of $10 \mathrm{~m} \times 10 \mathrm{~m}$ through principal component analysis (PCA). We calculated the abundance of the five dominant trees (C. eyrei, S. superba, $Q$. glandulifera, C. glauca, and P. massoniana), tree species richness, rarefied tree species richness [21] and tree density in each plot. We also tested the differences of abiotic and biotic factors among the habitats and elevations, and analyzed the relationships between coarse root density and abiotic and biotic factors using a general linear model, two-way ANOVA and linear regression.

ANOVA and linear regression were completed using SPSS 16.0, and calculation of abiotic and biotic factors was conducted using R software [22]. Significant differences in two-way ANOVA were subjected to Duncan's tests. Figures were created using SigmaPlot 10.0.

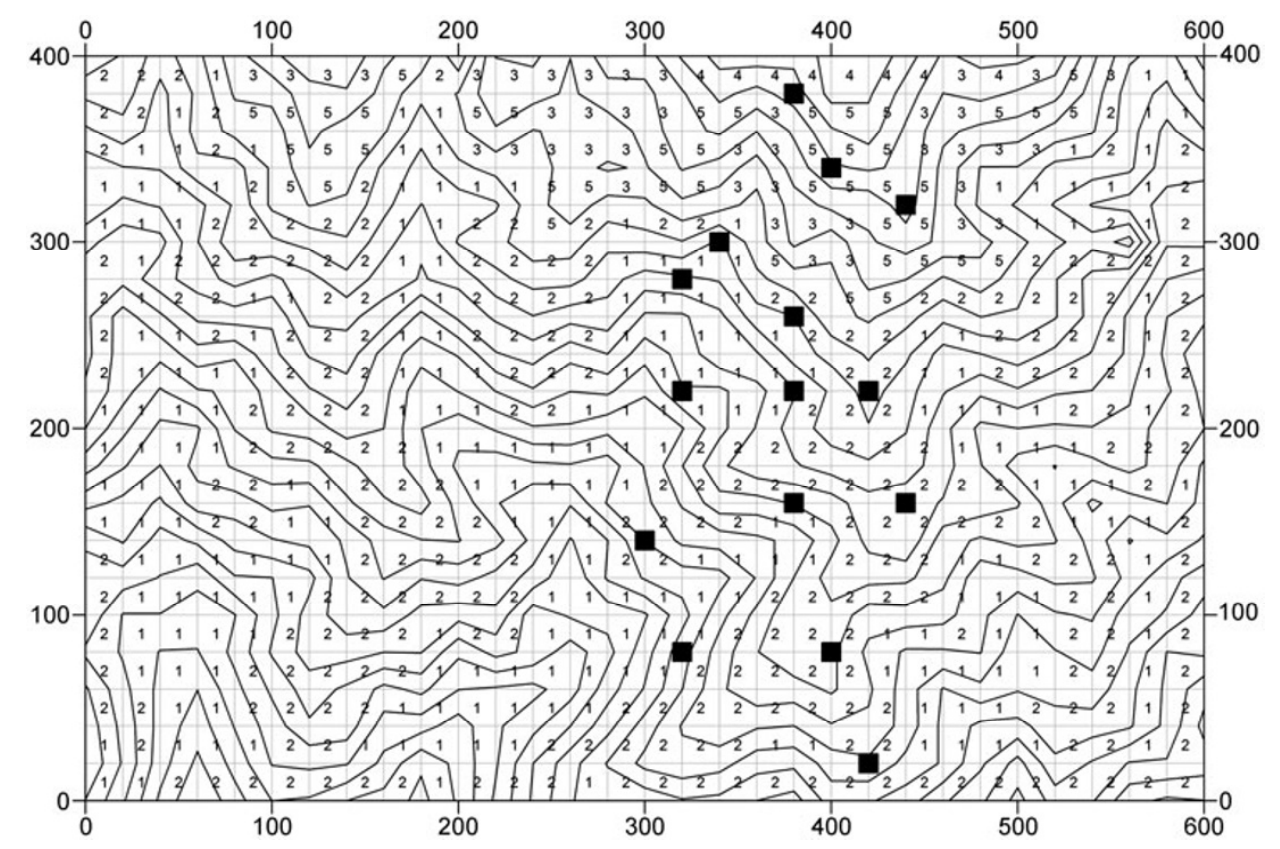

Figure 1 GPR scanned plots in the ridge, slope and valley habitat of the $24-\mathrm{hm}^{2}$ permanent plot on the GNNR. 


\section{Results}

\subsection{Coarse root density}

The effect of habitat on coarse root density was significant $(P<0.001)$. The overall average coarse root density was 88.04 roots $\mathrm{m}^{-2}$ with the measure for three habitats at 94.98 , 79.58 , and 89.56 roots $\mathrm{m}^{-2}$ in ridge, slope and valley, respectively (Figure 2A). The coarse root density was also significantly different among the three soil depths $(P<0.001)$ of $0-20,20-40$, and $40-60 \mathrm{~cm}$. Almost $95.61 \%$ of the coarse roots were distributed in the $0-40 \mathrm{~cm}$ soil layer regardless of habitat and elevation (Figure 2B and D). Root density at the soil surface $0-20 \mathrm{~cm}$ was not significantly different among habitats. For the deeper soil $(40-60 \mathrm{~cm})$, coarse root density on ridges was significantly higher than those in slopes and valleys.

As the elevations of sampled plots gradually decreased from level 1 to level 5 (i.e., 204.1, 181.0, 154.0, 124.2, and $102.9 \mathrm{~m}$, respectively), the coarse root density ranged from 79.35 to 93.42 roots $\mathrm{m}^{-2}$. The lowest coarse root density occurred at the lowest elevation $(P<0.05$; Figure 2C). For each soil layer, coarse root density differed significantly among the five elevations ( $P<0.05$; Figure 2D).

There was significant interactive effect of plot elevation and habitat on coarse root density $(P<0.001$; Figure $2 \mathrm{E})$. For higher elevations, e.g., level 2 and level 3, higher coarse root density occurred on the ridges than in the slopes and valleys. However, for lower elevations (e.g., level 5), the highest coarse root density was found on the slopes.

We classified roots into three size classes (coarse root diameter): $1-2,2-3$, and $>3 \mathrm{~cm}$ diameter. Coarse roots $>3 \mathrm{~cm}$ in diameter occurred more frequently in the valleys than in the ridges and slopes $(P<0.05)$. However, root size was not significantly different based on elevation $(P>0.05)$. There were no interactive effects of habitat and elevation on root size (Figure 2F and G). Soil depth had major impact on the distribution of coarse roots $(P<0.05)$. Smaller $1-2 \mathrm{~cm}$ diameter roots occurred more frequently in the surface soil layer $(P<0.05)$ while $>3 \mathrm{~cm}$ diameter roots occurred mostly in the deeper 20-40 cm soil layer $(P<0.05$; Figure $2 \mathrm{H})$.

The means of the coarse root densities for $C$. eyrei and $S$. superba were 108.56 and 102.00 roots $\mathrm{m}^{-2}$, respectively, with the average 105.94 roots $\mathrm{m}^{-2}$. Soil depth had significant effects on coarse root distribution $(P<0.001)$, and the proportion of coarse roots among the three soil layers at $0-20,20-40$, and $40-60 \mathrm{~cm}$ was $52.35 \%, 39.38 \%$ and $8.28 \%$, respectively. Although there was no significant difference in coarse root density between $C$. eyrei and $S$. superba across the three soil depths $(P>0.05), C$. eyrei had more roots in deeper soils (Figure 3 ).

\subsection{Abiotic factors}

PCA results on topography at the $10 \mathrm{~m} \times 10 \mathrm{~m}$ scale (Table 1) showed that the first principal component explained as much as $96.96 \%$ of the variation, and the means of elevation and the slope were the most important factors.

Furthermore, there was significant difference in the means of the elevations and the slopes among three habitats $(P<0.01$; Table2).

Table 3 shows that there was significant linear regression $(P<0.05)$ between the coarse root density and slope at the soil depth of 40-60 cm with explanation power of $23.2 \%$.

\subsection{Biotic factors}

\subsubsection{Tree species richness and tree density}

There was significant $(P<0.05)$ difference in tree species richness and rarefied tree species richness, which excludes the impacts of individual numbers, among the three habitats. Tree species richness differed significantly among the five elevations $(P<0.05$; Table 4$)$.

Table 1 PCA of topography at a $10 \mathrm{~m} \times 10 \mathrm{~m}$ scale

\begin{tabular}{crrr}
\hline Topography properties & PC1 & PC2 & PC3 \\
\hline Mean elevation & -12.820 & -0.057 & -0.008 \\
Convex & 0.031 & 0.736 & -0.630 \\
Slope & 0.368 & -2.037 & -0.228 \\
Aspect & -0.016 & -0.044 & 0.015 \\
Eigenvalues & 1992.966 & 56.907 & 5.449 \\
Proportion Explained & 0.970 & 0.028 & 0.003 \\
Cumulative proportion & 0.970 & 0.997 & 0.99995 \\
\hline
\end{tabular}

Table 2 Differences in topography among three habitats and five elevation levels ${ }^{\text {a) }}$

\begin{tabular}{cccc}
\hline$F$-value & Topography & Mean elevation & Slope \\
\hline Habitats & $54.180^{* *}$ & $53.257^{* *}$ & $8.961^{* *}$ \\
Elevation levels & $75.895^{* *}$ & $75.068^{* *}$ & $0.341^{\text {ns }}$ \\
\hline
\end{tabular}

a) ns, $P>0.05 ; * *, P<0.01$.

Table 3 Linear regressions between coarse root density in different soil depths and root sizes, and terrain properties ${ }^{\text {a) }}$

\begin{tabular}{cccc}
\hline $\begin{array}{c}\text { Soil depth or root diameter } \\
\text { /adjusted } R^{2}\end{array}$ & Topography & $\begin{array}{c}\text { Mean } \\
\text { elevation }\end{array}$ & Slope \\
\hline $0-20 \mathrm{~cm}$ & $-0.054^{\mathrm{ns}}$ & $-0.054^{\mathrm{ns}}$ & $-0.075^{\mathrm{ns}}$ \\
$20-40 \mathrm{~cm}$ & $-0.063^{\mathrm{ns}}$ & $-0.063^{\mathrm{ns}}$ & $-0.030^{\mathrm{ns}}$ \\
$40-60 \mathrm{~cm}$ & $-0.044^{\mathrm{ns}}$ & $-0.043^{\mathrm{ns}}$ & $0.232^{*}$ \\
$1-2 \mathrm{~cm}$ & $-0.013^{\mathrm{ns}}$ & $-0.014^{\mathrm{ns}}$ & $0.006^{\mathrm{ns}}$ \\
$2-3 \mathrm{~cm}$ & $-0.062^{\mathrm{ns}}$ & $-0.062^{\mathrm{ns}}$ & $-0.069^{\mathrm{ns}}$ \\
$>3 \mathrm{~cm}$ & $-0.024^{\mathrm{ns}}$ & $-0.025^{\mathrm{ns}}$ & $0.191^{\mathrm{ns}}$ \\
Total coarse root density & $-0.076^{\mathrm{ns}}$ & $-0.076^{\mathrm{ns}}$ & $0.014^{\mathrm{ns}}$ \\
\hline
\end{tabular}

a) ns, $P>0.05 ; *, P<0.05$.

Table 4 Differences of tree species richness, rarefied tree species richness and tree density among three habitats, and five elevations ${ }^{\text {a) }}$

\begin{tabular}{cccc}
\hline$F$-value & $\begin{array}{c}\text { Tree species } \\
\text { richness }\end{array}$ & $\begin{array}{c}\text { Rarefied tree species } \\
\text { richness }\end{array}$ & Tree density \\
\hline Habitats & $7.514^{*}$ & $14.422^{* *}$ & $0.338^{\mathrm{ns}}$ \\
Elevations & $4.609^{*}$ & $0.852^{\mathrm{ns}}$ & $2.518^{\mathrm{ns}}$ \\
\hline
\end{tabular}

a) ns, $P>0.05 ; *, P<0.05$; **, $P<0.01$. 

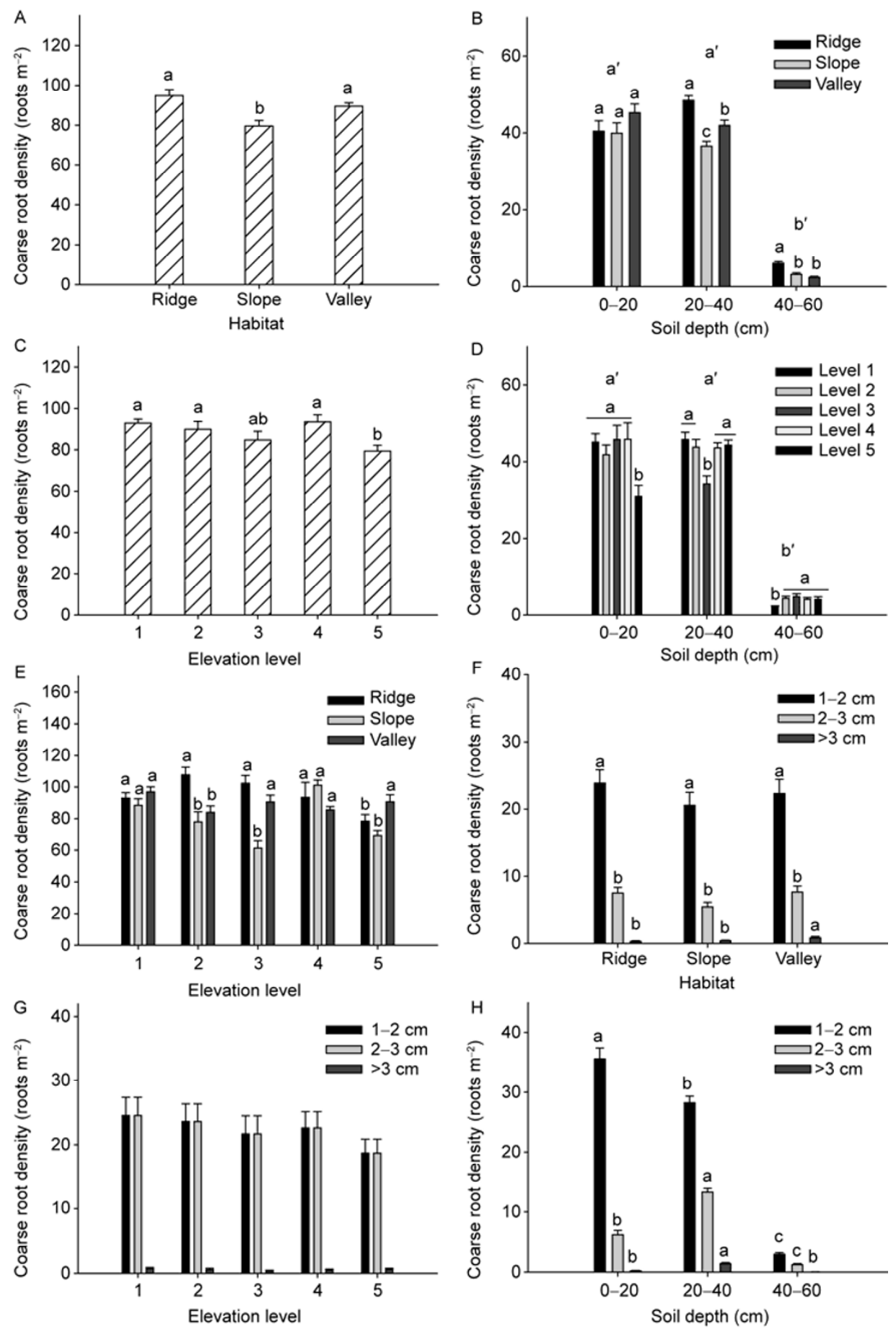

Figure 2 Effects of habitat (A), interaction of habitat and soil depth (B), elevation (C), interaction of elevation and soil depth (D), interaction of elevation and habitat $(\mathrm{E})$, interaction of habitat and root size $(\mathrm{F})$, interaction of elevation and root size $(\mathrm{G})$, and interaction of soil depth and root size $(\mathrm{H})$ on coarse root density. Means with the different letters are significantly different from each other $(P<0.05)$.

Although there were no significant relationships $(P>0.05)$ at a soil depth of 0-40 cm (Table 5), coarse root density was correlated negatively with tree species richness in the 40-60 $\mathrm{cm}$ soil layer $(P<0.05$; Figure 4$)$. Moreover, the explanation power of tree species richness and rarefied tree species richness for coarse root density at depths of 40-60 cm was as high as $52.3 \%$ and $29.8 \%$, respectively. No significant linear relationships were found between root size, tree richness and tree density $(P>0.05)$. For the total coarse root density at depths of 0-60 cm, no significant effects of the three abiotic factors were found.

\subsubsection{Abundance of dominant trees and DBH}

Table 6 shows the numbers of dominant tree species, $C$. 


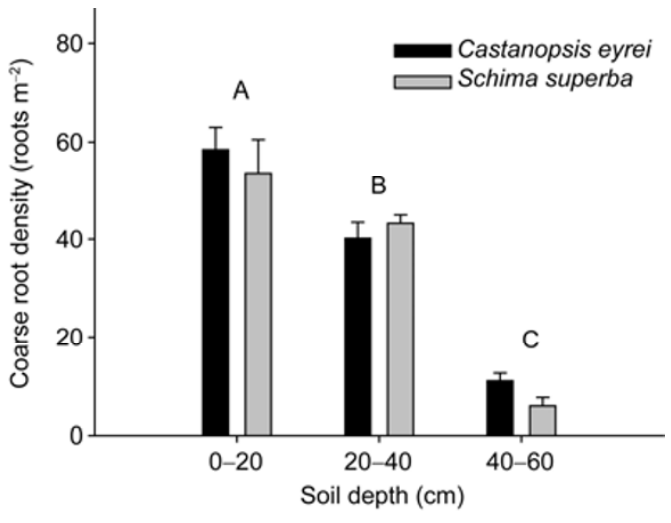

Figure 3 Effects of soil depth on coarse root density in Castanopsis eyrei and Schima superb. Means with the different letters are significantly different from each other $(P<0.05)$.

Table 5 Linear regressions between the combination of coarse root density and root size, and the three factors of tree species richness, rarefied tree species richness and tree density in soils of different depths ${ }^{\mathrm{a}}$ )

\begin{tabular}{cccc}
\hline $\begin{array}{c}\text { Soil depth or root } \\
\text { diameter } \\
\text { /adjusted } R^{2}\end{array}$ & $\begin{array}{c}\text { Tree species } \\
\text { richness }\end{array}$ & $\begin{array}{c}\text { Rarefied tree } \\
\text { species richness }\end{array}$ & Tree density \\
\hline $0-20 \mathrm{~cm}$ & $-0.004^{\mathrm{ns}}$ & $-0.052^{\mathrm{ns}}$ & $-0.072^{\mathrm{ns}}$ \\
$20-40 \mathrm{~cm}$ & $0.023^{\mathrm{ns}}$ & $0.013^{\mathrm{ns}}$ & $-0.055^{\mathrm{ns}}$ \\
$40-60 \mathrm{~cm}$ & $0.523^{\text {*** }}$ & $0.298^{*}$ & $0.078^{\mathrm{ns}}$ \\
$1-2 \mathrm{~cm}$ & $-0.072^{\mathrm{ns}}$ & $-0.076^{\mathrm{ns}}$ & $-0.062^{\mathrm{ns}}$ \\
$2-3 \mathrm{~cm}$ & $-0.077^{\mathrm{ns}}$ & $0.026^{\mathrm{ns}}$ & $0.005^{\mathrm{ns}}$ \\
$>3 \mathrm{~cm}$ & $-0.023^{\mathrm{ns}}$ & $0.092^{\mathrm{ns}}$ & $-0.072^{\mathrm{ns}}$ \\
Total coarse root density & $-0.065^{\mathrm{ns}}$ & $-0.047^{\mathrm{ns}}$ & $-0.070^{\mathrm{ns}}$ \\
\hline
\end{tabular}

a) ns, $P>0.05$; * $P<0.05$; ***, $P<0.001$.

eyrei, S. superba, Q. glandulifera, C. glauca, and P. massoniana, in each subplot. The numbers of $Q$. glandulifera and $C$. glauca differed significantly among the three habitats $(P<0.05$; Table 7$)$.

For the $0-20 \mathrm{~cm}$ soil layer, there was no significant relationship between the coarse root density and the abundances of dominant trees $(P>0.05$; Table 8$)$. Coarse root density changed linearly and negatively with the number of $C$. glauca trees $(P<0.05)$ in the soil depth of $20-40 \mathrm{~cm}$ (Figure 5) with an explanation power of $29.5 \%$. Meanwhile, there was positively linear relationship between coarse root density and the abundance of $P$. massoniana in the deeper $40-60 \mathrm{~cm}$ soil with an explanation power of $23.4 \%$ (Figure $5)$. There were significantly negative relationships between the coarse root density ( $>3 \mathrm{~cm}$ roots) and the abundances of $C$. eyrei and $P$. massoniana $(P<0.05)$.

Table 6 Abundance of the five dominant species in each plot ${ }^{\mathrm{a})}$

\begin{tabular}{crrrrrr}
\hline Plot & CE & SS & QG & CG & PM & Sum \\
\hline Ridge 1 & 42 & 126 & 16 & 1 & 1 & 502 \\
Ridge 2 & 25 & 2 & 6 & 0 & 8 & 200 \\
Ridge 3 & 31 & 11 & 15 & 0 & 7 & 209 \\
Ridge 4 & 16 & 26 & 19 & 0 & 0 & 225 \\
Ridge 5 & 30 & 3 & 8 & 0 & 4 & 110 \\
Slope 1 & 10 & 1 & 3 & 0 & 0 & 239 \\
Slope 2 & 55 & 45 & 5 & 2 & 2 & 319 \\
Slope 3 & 39 & 4 & 0 & 4 & 3 & 227 \\
Slope 4 & 9 & 9 & 3 & 2 & 2 & 109 \\
Slope 5 & 23 & 3 & 0 & 3 & 0 & 149 \\
Valley 1 & 14 & 2 & 3 & 4 & 0 & 310 \\
Valley 2 & 12 & 1 & 0 & 4 & 0 & 212 \\
Valley 3 & 22 & 4 & 0 & 9 & 0 & 273 \\
Valley 4 & 35 & 4 & 1 & 2 & 5 & 255 \\
Valley 5 & 8 & 6 & 0 & 1 & 0 & 164 \\
\hline
\end{tabular}

a) CE, SS, QG, CG, and PM represent Castanopsis eyrei, Schima superba, Quercus glandulifera, Cyclobalanopsis glauca, and Pinus massoniana, respectively.

Table 7 Two-way ANOVA between habitats and elevations for dominant species abundance at a $10 \mathrm{~m} \times 10 \mathrm{~m}$ scale ${ }^{\text {a) }}$

\begin{tabular}{cccccc}
\hline$F$-value & CE & SS & QG & CG & PM \\
\hline Habitat & $0.649^{\mathrm{ns}}$ & $1.013^{\mathrm{ns}}$ & $19.107^{* *}$ & $5.065^{*}$ & $1.869^{\mathrm{ns}}$ \\
Elevation & $0.357^{\mathrm{ns}}$ & $0.616^{\mathrm{ns}}$ & $1.293^{\mathrm{ns}}$ & $1.336^{\mathrm{ns}}$ & $0.718^{\mathrm{ns}}$ \\
\hline
\end{tabular}

a) CE, SS, QG, CG, and PM represent Castanopsis eyrei, Schima superba, Quercus glandulifera, Cyclobalanopsis glauca, and Pinus massoniana, respectively. ns, $P>0.05 ; *, P<0.05 ; * *, P<0.01$.
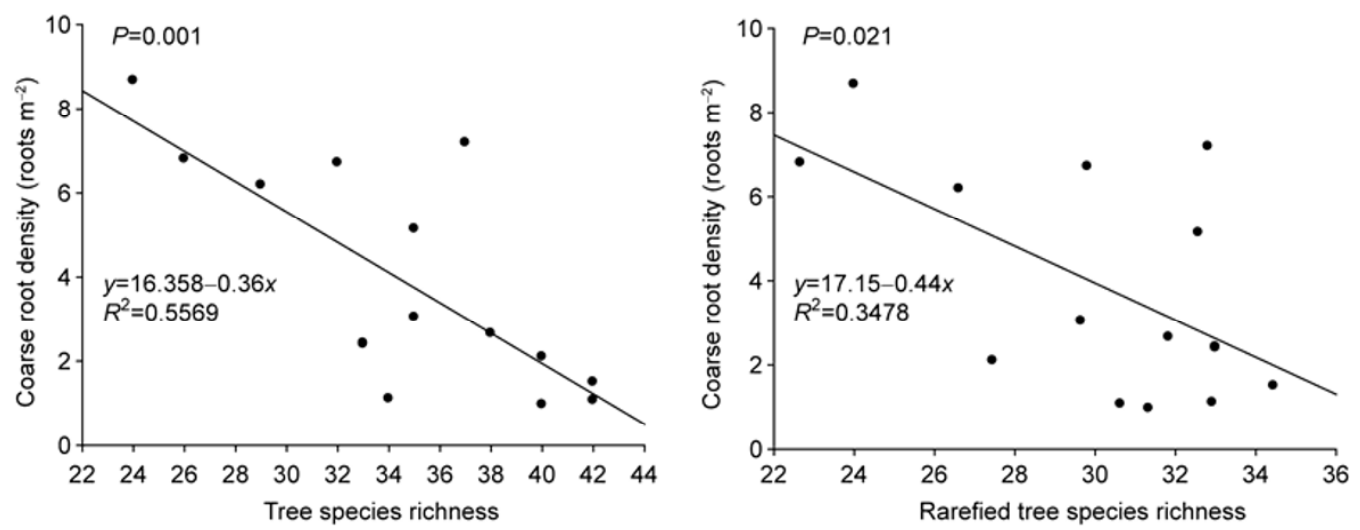

Figure 4 Negatively linear regressions between coarse root density and tree species richness and between coarse root density and rarefied tree species richness in the soil depth of $40-60 \mathrm{~cm}$. 
Table 8 Linear regressions between coarse root density and abundance of the five dominant tree species with different soil depth and root size

\begin{tabular}{|c|c|c|c|c|c|c|c|}
\hline $\begin{array}{l}\text { Soil depth or root diameter } \\
\text { /adjusted } R^{2}\end{array}$ & $\mathrm{CE}$ & SS & QG & CG & PM & $\begin{array}{c}\text { Multi- } \\
\text { regression }\end{array}$ & $\begin{array}{l}\text { Stepwise } \\
\text { regression }\end{array}$ \\
\hline $0-20 \mathrm{~cm}$ & $0.060^{\mathrm{ns}}$ & $-0.074^{\mathrm{ns}}$ & $-0.075^{\text {ns }}$ & $-0.026^{\mathrm{ns}}$ & $-0.073^{\text {ns }}$ & $-0.001^{\mathrm{ns}}$ & $\mathrm{ns}$ \\
\hline $20-40 \mathrm{~cm}$ & $-0.072^{\mathrm{ns}}$ & $0.000^{\mathrm{ns}}$ & $0.115^{\mathrm{ns}}$ & $0.295^{*}$ & $0.055^{\mathrm{ns}}$ & $0.296^{\mathrm{ns}}$ & $0.295^{*} \mathrm{CG}$ \\
\hline $40-60 \mathrm{~cm}$ & $-0.068^{\mathrm{ns}}$ & $-0.024^{\mathrm{ns}}$ & $0.072^{\mathrm{ns}}$ & $0.097^{\mathrm{ns}}$ & $0.234^{*}$ & $0.284^{\mathrm{ns}}$ & $0.234^{*} \mathrm{PM}$ \\
\hline $1-2 \mathrm{~cm}$ & $-0.028^{\mathrm{ns}}$ & $-0.077^{\mathrm{ns}}$ & $-0.030^{\mathrm{ns}}$ & $0.032^{\mathrm{ns}}$ & $0.190^{\mathrm{ns}}$ & $0.468^{\mathrm{ns}}$ & ns \\
\hline $2-3 \mathrm{~cm}$ & $-0.056^{\mathrm{ns}}$ & $-0.030^{\mathrm{ns}}$ & $0.033^{\mathrm{ns}}$ & $0.017^{\mathrm{ns}}$ & $-0.056^{\mathrm{ns}}$ & $0.284^{\mathrm{ns}}$ & ns \\
\hline$>3 \mathrm{~cm}$ & $0.259^{*}$ & $0.021^{\mathrm{ns}}$ & $0.074^{\mathrm{ns}}$ & $0.015^{\mathrm{ns}}$ & $0.215^{*}$ & $0.170^{\mathrm{ns}}$ & $0.259^{*} \mathrm{CE}$ \\
\hline Total coarse root density & $0.071^{\mathrm{ns}}$ & $-0.070^{\mathrm{ns}}$ & $0.096^{\mathrm{ns}}$ & $-0.003^{\mathrm{ns}}$ & $0.012^{\mathrm{ns}}$ & $0.570^{*}$ & ns \\
\hline
\end{tabular}

a) ns, $P>0.05 ; *, P<0.05$.
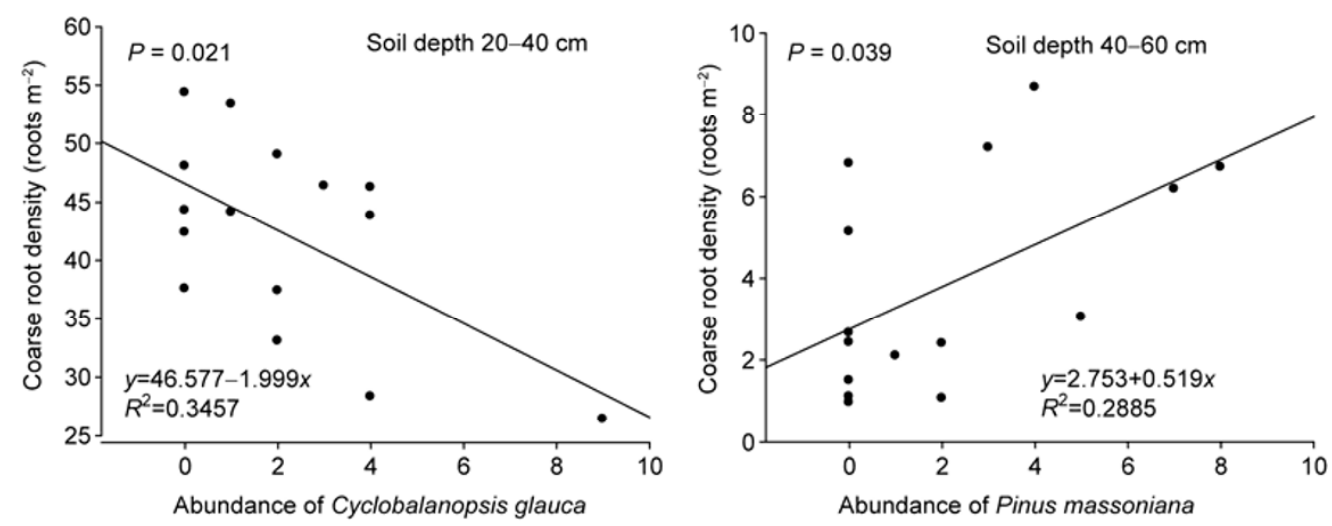

Figure 5 Linear regressions between coarse root density and abundance of Cyclobalanopsis glauca and Pinus massoniana.

Although there were no significantly linear relationships between the total coarse root density and the abundance of each dominant tree species across all three root diameter classes $(P>0.05)$, the multi-regression result showed that the abundances of the five dominant trees interplayed on the coarse root density $(P<0.05)$ with high explanation power of $57 \%$. The fitted empirical equation was expressed as follows:

$$
\begin{aligned}
& \text { Coarse root density=93.54-0.97 } X_{\mathrm{CE}^{+}} \\
& 0.25 X_{\mathrm{SS}}+0.53 X_{\mathrm{QG}}+1.58 X_{\mathrm{CG}^{+}}+3.94 X_{\mathrm{PM}} \text {. }
\end{aligned}
$$

Additionally, the explanation power of DBH for coarse root density was very low, regardless of the soil depth. The effect of DBH on coarse root density was not significant $(P>0.05)$.

\section{Discussion}

\subsection{The estimation of coarse root density}

The spatial distribution of roots determines the ability of a plant to access and exploit soil resources, to some extent. Our study found that coarse roots were mainly distributed at depths of $0-40 \mathrm{~cm}$ in a subtropical evergreen broad-leaved forest. This was consistent with the results from tundra, boreal coniferous forests, temperate grasslands, deserts and temperate coniferous forests [5]. Generally, coarse root density decreased with soil depth. Therefore, the $40-60 \mathrm{~cm}$ soil layer had fewer coarse roots than the upper soil layers. Cheng et al. [23] also confirmed that coarse roots with diameters $>10 \mathrm{~cm}$ collected by soil augers were gathered from soil depths of $20-60 \mathrm{~cm}$ for roots from five vertical soil intervals, $0-10,10-20,20-30,30-40$, and $40-60 \mathrm{~cm}$, in a $P$. massoniana plantation forest. In particular, our field work found more coarse roots with diameter above $3 \mathrm{~cm}$ occurred in valleys, compared with soils from slopes and ridges.

Hruska et al. [18] indicated that the numbers of coarse roots of Quercus petraea increased from the depth of $20 \mathrm{~cm}$ to $1.6 \mathrm{~m}$ as measured by GPR. In our study, coarse root density increased vertically in the soil depth range of $0-40 \mathrm{~cm}$ but decreased sharply as with soil depth $>40 \mathrm{~cm}$, which partially overlapped with the results of Hruska et al. Our study site in the Gutianshan National Nature Reserve was classified as having a subtropical monsoon climate which featured considerable surface runoff. Coarse roots occurred in relatively shallow soil. Therefore, soil characteristics should have more directly impacted on the coarse root distribution; also, soil depth significantly affected the size of coarse roots in our study. Coarse roots with 1-2 cm diameters were found more frequently in the soil surface, while the roots $>2$ $\mathrm{cm}$ in diameter occurred more frequently at depths of 20-40 $\mathrm{cm}$. The proportion of large roots decreased in deeper soil. Soil moisture, temperature and nutrients interacted and all of these contributed to root growth creating the patterns of both of vertical and horizontal root distribution. The fact that coarse root density was higher near the trunk than in 
open areas away from tree trunks indicated that plants allocated more nutrients to form coarse roots near the trunk. This pattern was consistent with the coarse root distribution of Fagus sylvatica and Q. petraea [12].

Liu and Man [24] indicated that aside from the conspicuously vertical differences in coarse root (root diameter $>3$ $\mathrm{mm}$ ) for Populus simonii, more coarse roots were found in the upper slopes than the lower slopes. Similarly, we found a higher coarse root density on the ridges compared with that in the slopes. For the middle and deeper soil depth, the coarse root densities on the ridges were significantly higher than those in the slopes or valleys.

The mean of coarse root density of 88.04 roots $\mathrm{m}^{-2}$ measured by GPR in our study was relatively low compared with the value range of $20-4420$ roots $\mathrm{m}^{-2}$ noted in agro-forest ecosystem studies [25]. However, our results mainly focus on coarse roots in contrast to the data for total fine and coarse roots, which also implies that GPR appears to have great potential for detecting root density.

\subsection{Relationships between coarse root density and abi- otic or biotic factors}

The significantly negative relationships between coarse root density and tree species richness, rarefied tree species richness in our study showed that both of the numbers of individual and species had great effects on the patterns of coarse root distribution. The negative relationship between fine root spatial distribution, e.g., root density and root number, and tree species richness also implied that intense interspecific and/or intraspecific competition occurred on the sites with high fine root density [26,27]. Brisson and Reynolds [28] proposed a spatial distribution model for root competition, suggesting that competition from neighboring trees tends to lead to root competition for soil space.

Intensive competition, caused by high tree density, leads to a decrease in the size of the aboveground parts of plants and to high levels of competition for roots [29]. Unlike the active function of fine roots in the absorption of nutrients, the main function of coarse roots is to support and stabilize the aboveground parts of a tree. This may partly explain why there was no obvious relationship between coarse root (diameter $\geqslant 1.5 \mathrm{~cm}$ ) density and tree density.

Since coarse roots are responsible for supporting the entire tree, most studies showed mature trees have extensive coarse root systems, and found a close relationship between coarse root density and tree size across all soil depths $[11,15]$. Unfortunately, our study did not support this, although our measurements involved a rather large area.

Some studies on aboveground processes in forest ecosystem have suggested that dominant individuals successfully acquire the majority available resources in an ecosystem and overwhelm other individuals [30]. Our results also showed significant relationships between the abundances of five dominant tree species and coarse root density, although coarse roots tended to dominate the soil surface layer, suggesting that coarse root distribution within this layer was random, regardless of the dominant trees. The abundance of the dominant species, specifically the larger number of $P$. massoniana trees and the limited number of $C$. glauca trees, may explain the phenomena that coarse root density on the ridges was higher than in the slopes and valleys.

In general, our study showed that coarse roots mainly occurred in the $0-40 \mathrm{~cm}$ soil layer. Also, the terrain, tree species richness, rarefied tree species richness and tree density had no significant impact on coarse root density in this soil layer. That is, the soil depth of $0-40 \mathrm{~cm}$ was the "basic distribution layer" for coarse roots for most species and individuals. Soil layers $<40 \mathrm{~cm}$ deep were regard as "potential distribution layers" for coarse roots, since the effects of abiotic and biotic factors on coarse root density were significant. Xie [14] has also suggested that plants can avoid spatial overlap and interruption from neighboring tree roots by producing more coarse roots in deeper soils thus alleviate the pressures from competition.

The authors thank Yang Bo, Man XingXing, Liu XiaoJuan and He TuFa for assisting with data analysis and field work. The authors also thank the invaluable comments and suggestions from anonymous reviewers. This work was supported by the National Natural Science Foundation of China (31170457, 30710103907).

1 Stover D B, Day F P, Butnor J R, et al. Effect of elevated $\mathrm{CO}_{2}$ on coarse-root biomass in Florida scrub detected by ground-penetrating radar. Ecology, 2007, 88: 1328-1334

2 Resh S C, Battaglia M, Worledge D, et al. Coarse root biomass for eucalypt plantations in Tasmania, Australia: Sources of variation and methods for assessment. Trees-Struct Funct, 2003, 17: 389-399

3 Day F P, Weber E P, Hinkle C, et al. Effects of elevated atmospheric $\mathrm{CO}_{2}$ on fine root length and distribution in an oak-palmetto scrub ecosystem in central Florida. Global Change Biol, 1996, 2: 143-148

4 Misra R, Turnbull C, Cromer R, et al. Below- and above-ground growth of Eucalyptus nitens in a young plantation: I Biomass. Forest Ecol Manag, 1998, 106: 283-293

5 Harding R, Gale M, Grigal D. Soil productivity index: Predictions of site quality for white spruce plantations. Soil Sci Soc Am J, 1991, 55: 1701-1708

$6 \mathrm{Li} \mathrm{L} \mathrm{H.} \mathrm{Biomass} \mathrm{allocation} \mathrm{in} \mathrm{mixed} \mathrm{forest} \mathrm{of} \mathrm{Cunninghamia} \mathrm{lanceo-}$ lata and Tsoongiodendron odorum (in Chinese). J Fujian College Forest, 2003, 23: 297-300

7 Li Y Y, Fan H B. Spatial structure of biomass and nutrients in the mixed Pinus massoniana-Michelia macclurei Plantation (in Chinese). Acta Agricult Univ Jiangxi, 2005, 27: 700-704

8 Zhang J E, Li Y L, Huang D Z, et al. Root distribution pattern of Mulberry shoots intercropped with Peanut and its influence on soil moisture and nutrient in Qian'an. J Soil Water Conserv, 2007, 21: 38-42

9 Ren A Z, Gao Y B, Wang J L. Root distribution and canopy structure of Salix gordejevii in different sandy land habitats. Acta Eco Sin, 2001, 21: 399-404

10 Archer E, Strauss H. Effect of plant density on root distribution of three-year-old grafted 99 Richter grapevines. S Afr J Enol Vitic, 1985, 6: $25-30$

11 Schroth G. Tree root characteristics as criteria for species selection and systems design in agroforestry. Agroforest Syst, 1995, 30: 125-143 
12 Leuschner C, Hertel D, Coners H, et al. Root competition between beech and oak: a hypothesis. Oecologia, 2001, 126: 276-284

13 Liu C J, Guo X L, Xu Z Q. Roots study on mixed forest of Pinus tabulaeformis Carr. and Quercus variabilis Blume in Beijing (in Chinese). J Beijing Forest College, 1985, 77-84

14 Xie Y, An S, Wu B, et al. Density-dependent root morphology and root distribution in the submerged plant Vallisneria natans. Environ Exp Bot, 2006, 57: 195-200

15 Bi H, Turvey N D, Heinrich P. Rooting density and tree size of Pinus radiata (D. Don) in response to competition from Eucalyptus obliqua (L'Herit). Forest Ecol Manag, 1992, 49: 31-42

16 Wielopolski L, Hendrey G, Daniels J, et al. Imaging tree root systems in situ. In: Proceedings of the 8th International Conference on Ground Penetrating Radar, Gold Cost, Australia, 2000. 642-646

17 Daniels D J, ed. Ground Penetrating Radar. Wiley Online Library, 2004

18 Hruska J, Čermák J, Šustek S. Mapping tree root systems with ground-penetrating radar. Tree Physiol, 1999, 19: 125-130

19 Butnor J R, Doolittle J, Kress L, et al. Use of ground-penetrating radar to study tree roots in the southeastern United States. Tree Physiol, 2001, 21: 1269-1278

$20 \mathrm{Hu}$ Z H, Yu M J, Ding B B, et al. Types of evergreen broad-leaved forests and the species diversity in Gutian Mountain Nature Reserve. Chin J Appl Environ Biol, 2003, 9: 341-345

21 Molino J F, Sabatier D. Tree diversity in tropical rain forests: A validation of the intermediate disturbance hypothesis. Science, 2001, 294 : 1702-1704
22 R Development Core Team. R: A Language and Environment for Statistical Computing. R Foundation for Statistical Computing, Vienna, Austria, 2009. http://www.R-project.org

23 Cheng R M, Wang R L, Xiao W F, et al. Spatial distribution of root biomass of Pinus massoniana plantation in Three Gorges Reservoir area, China. Acta Eco Sin, 2012, 32: 823-832

24 Liu X, Man X L. Distribution patterns of root systems of Populus simonii Carr. in highland of Mu Us Sandland. J Soil Water Conserv, 2008, 6: 48-53

25 Tufekcioglu A, Raich J, Isenhart T, et al. Fine root dynamics, coarse root biomass, root distribution and soil respiration in a multispecies riparian buffer in Central Iowa, USA. Agroforest Syst, 1998, 44: 163-174

26 Majdi H, Persson H. Spatial distribution of fine roots, rhizosphere and bulk soil chemistry in an acidified Picea abies stand. Scand J Forest Res, 1993, 8: 147-155

27 Büttner V, Leuschner C. Spatial and temporal patterns of fine root abundance in a mixed oak-beech forest. Forest Ecol Manag, 1994, 70: 11-21

28 Brisson J, Reynolds J F. The effect of neighbors on root distribution in a creosote bush (Larrea tridentata) population. Ecology, 1994, 75: 1693-1702

29 Casper B B, Jackson R B. Plant competition underground. Annu Rev Eco Syst, 1997, 28: 545-570

30 Stegen J C, Hurlbert A H. Inferring ecological processes from taxonomic, phylogenetic and functional trait $\beta$-diversity. PLoS ONE, 2011, 6: e20906

Open Access This article is distributed under the terms of the Creative Commons Attribution License which permits any use, distribution, and reproduction in any medium, provided the original author(s) and source are credited. 